\title{
Comparing the Sensitivity of Microscopy to Diagnostic Strip in the Survey for Urinary Schistosomiasis
}

\author{
Nathaniel Yacham Musa*, Anthony John Dadah \\ Microbiology Department, Kaduna State University, Kaduna, Nigeria \\ Email address: \\ tonydadah@yahoo.com (A. J. Dadah), yachamusa@gmail.com (N. Y. Musa) \\ ${ }^{*}$ Corresponding author
}

To cite this article:

Nathaniel Yacham Musa, Anthony John Dadah. Comparing the Sensitivity of Microscopy to Diagnostic Strip in the Survey for Urinary Schistosomiasis. Bioprocess Engineering. Vol. 2, No. 1, 2018, pp. 14-19. doi: 10.11648/j.be.20180201.14

Received: March 1, 2018; Accepted: March 22, 2018; Published: April 12, 2018

\begin{abstract}
Schistosomiasis is one of the Neglected Tropical Diseases (NTDs) recording high morbidity and mortality rate for developing countries in Africa, South America, the Caribbean, the Middle East, and Asia. The sensitivity of microscopy to the use of diagnostic strip in the survey for urinary schistosomiasis among students attending some selected secondary schools was investigated in Chikun Local Government Area of Kaduna State, Nigeria. Four hundred and sixty two (462) urine samples were collected and examined for the eggs of Schistosoma haematobium using sedimentation and microscopy method. Microhaematuria and proteinuria were investigated using combi 11 test strips. This study revealed $11.5 \%$ prevalence rate for urinary schistosomiasis among the studied subjects based on direct egg detection method, 22.9\% based on micro-haematuria detection and $44.8 \%$ based on proteinuria. The sensitivity of Urine dip strip when compared to direct egg detection methods, shows that there is high sensitivity on the use of urine dip strip.
\end{abstract}

Keywords: Microscopy, Urine Samples, Ova of Schistosoma haematobium, Microhaematuria, Proteinuria, Nitrite, Leucocytes

\section{Introduction}

Urinary schistosomiasis is caused by Schistosoma haematobium. Schistosomes (blood flukes) are digenetic trematodes of the super family Schistosomatoidea. Hence, schistosomiasis is a helminthic water-borne disease [1]. There are two major forms of schistosomiasis which are intestinal and urogenital [2]. The affected people are largely hidden, concentrated in remote rural areas or urban slums and shanty towns. They are also largely silent, as the people affected or at risk have little political voice [3].

Health education is a key element of the schistosomiasis elimination effort. Because community life in Nigeria clustered around local rivers and ponds, the program's main message is to discourage people from urinating or defecating in water and encourage them to take praziquantel during community drug distribution [4]. Nigeria embarked on a national schistosomiasis control programme more than two decades ago and to date there is no systematic assessment available on the performance and outcome of the programme. Some argued that this may be because the intervention measures were not systematic and focused, and that there were no mapped baseline data of endemic communities upon which control outcome could have been assessed. Clearly, a rapid and cost-effective test tool that is reliable in the Nigerian environment would be indispensable for evolving such a map [5].

This study was aimed at comparing the use of direct egg detection method to the use of urine dip strip in assessing the incidence of urinary schistosomiasis among students attending some selected secondary schools in Chikun Local Government Area of Kaduna State, with the view of making recommendations that could contribute in reducing the spread of infection.

\section{Materials and Methods Gram's Iodine}

Urine samples were collected in sterile urine sample containers and taken to the laboratory in an iced packed flask. Hand gloves were used as protection against hands contamination. And formal saline was used to preserve the sample after carrying out the urine strip test using Combi 11 
dip strip. Gram's iodine was used to give a clearer background and detailed structure during microscopy.

\subsection{Description of Research Area}

Chikun Local Government Area of Kaduna State (Figure 1), Nigeria is located geographically between latitudes $10^{\circ}$ $03.00^{\prime} \mathrm{N}$ and $10^{\circ} 50.00^{\prime} \mathrm{N}$, and longitudes $6^{\circ} 40.00^{\prime} \mathrm{E}$ and $7^{\circ}$ $50.00^{\prime}$ E. Annual rainfall ranges between $850 \mathrm{~mm}$ to 1200 $\mathrm{mm}$. The mean monthly temperature varies between $20^{\circ} \mathrm{C}$ and $29^{\circ} \mathrm{C}$, depending on the season, but may increase up to $35^{\circ} \mathrm{C}$ at the end of the dry season. The area is drained by a network of rivers (Figure 2), the drainage pattern is dendritic and the streams are all subject to seasonal water level fluctuations [7-9]. The location of Dams, river and streams in Chikun Local Government Area encourages fishing, irrigation farming, block making, spiritual activities, and swimming. Most of the people prefer washing and bathing in the river after a long day work of farming, fishing, rock breaking and block making.

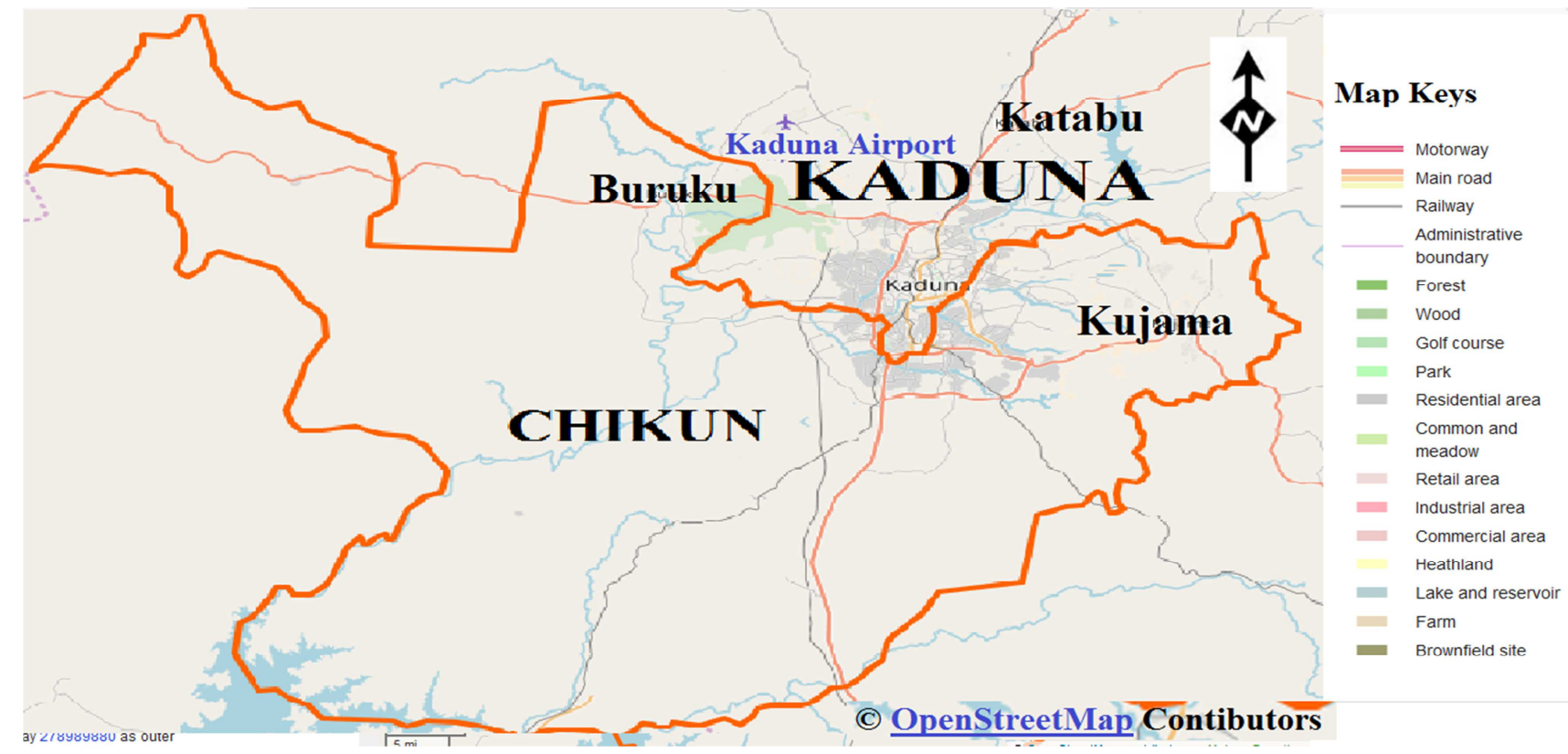

Figure 1. Map of Kaduna State Showing Chikun Local Government Area (Open Street Map Foundation, 2013).

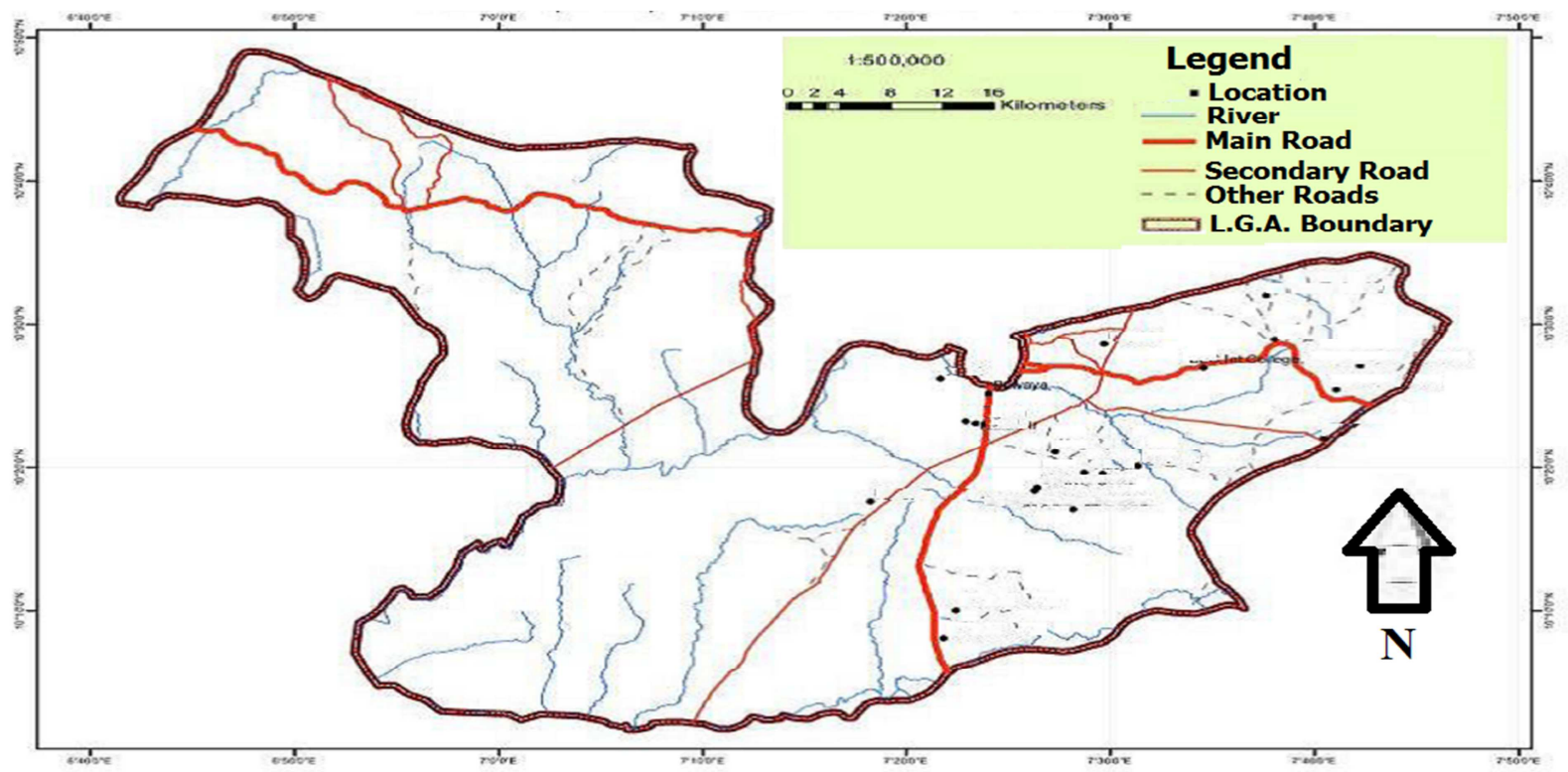

Figure 2. Drainage (Rivers) Map of Chikun Local Government Area of Kaduna State, Nigeria [9].

\subsection{Ethical Approval}

Ethical approval was obtained from Kaduna state Ministry of Health to conduct the research. Permission was obtained from the Kaduna State Ministry of Education through letter to the schools. Seven public schools and four private schools were contacted, all the public schools and one private school consented and participated. 


\subsection{Selection Criteria}

\subsubsection{Inclusion Criteria}

1. All consenting junior secondary school students ages 10 - 15 attending the selected schools in Chikun Local Government Area of Kaduna State in Nigeria. The class register contains the student's date of birth, thus their form masters/mistress were asked to select students within that age group and the students were further asked to confirmed their age.

2. All consenting students whose parent signed their consent form.

\subsubsection{Exclusion Criteria}

1. Non-consenting individuals were excluded from the study, Students not in the age group specified (10 15years) were not allowed to participate in the study,

2. Female students on menstrual period were not allowed to participate in the study,

3. Students not in the schools selected for study were not involved in the study.

\subsection{Sample Collection}

Consent forms and questionnaires were administered to junior secondary school students between the age group of 10 - 15 years. Sterile bottle containers were given to consenting students whose parents agreed by signing the consent forms. Urine samples were collected between the hours of $10 \mathrm{am}-$ $2 \mathrm{pm}$ in sterile screw cap sample bottle and a total of 462 samples were collected.

The sample size of 238 was calculated using the medical sample size prevalence formula [10] below, where $P$ is given as 19.5 [11]. However the need to cover large community leads to the increase in the population size.

$$
N=\frac{\left(z^{2}\right) p(1-p)}{d^{2}}
$$

$$
\begin{aligned}
& \text { Where } \\
& \mathrm{N}=? \\
& \mathrm{Z}=1.95 \\
& \mathrm{~d}=0.05 \\
& P=19.5 \\
& P=0.195
\end{aligned}
$$

\subsubsection{Sedimentation and Microscopy of the Urine Samples for the Ova of Schistosoma Haematobium}

Ten millilitres $(10 \mathrm{ml})$ of urine was dispensed in a test tube and centrifuged at 3000rpm for 5 minutes to concentrate the schistosomes' eggs. After centrifugation, the supernatant was discarded. The sediment was tapped and a drop was placed on a clean glass slide. A cover slip was placed on the drop. Wet mounts were examined microscopically using x 10 and $\mathrm{x} 40$ objectives of the light microscope for the characteristic eggs [6].

\subsubsection{Determination of Micro Haematuria using Combi 11 Strip}

$10 \mathrm{ml}$ of each urine sample was measured in a test tube and Combi 11 strip was immersed in the urine so that all reagent areas were well covered for $1 \mathrm{sec}$ and then removed from the sample. Excess urine was removed from the strip by wiping the edge of the strip on the urine container or on absorbent paper. The test strip was then read 60 seconds after dipping. The reading of the result was carried out by comparing the pad colours with the scale colours (Standard) provided by the manufacturer.

\subsubsection{Determination of Micro Proteinuria using Combi 11 Strip}

$10 \mathrm{ml}$ of urine sample was measured in a test tube and Combi 11 strip was immersed in the urine so that all reagent areas were well covered for $1 \mathrm{sec}$ and then removed from the sample. Excess urine was removed from the strip by wiping the edge of the strip on the urine container or on absorbent paper. The test was then read 60 seconds after dipping. The reading of the result was carried out by comparing the pad colours with the scale colours (Standard) provided by the manufacturer.

\subsubsection{Sensitivity of Microscopy to Diagnostic Strip Results Were Compared Using Statistical Analysis (Chi- squire)}

The use of microscopy to detect the presence of Ova of urinary Schistosomiasis was use as a reference standard, because the presence of Ova is a confirmation of active infection with no error of cross reaction. Even though the use of molecular techniques (ELISA) which is very sensitive could have been employed as reference standard but it is expensive and not readily available or accessible. Raw data generated were analysed on computer using IBM SPSS statistics software version 20. Chi-square was used to ascertain the possible associations at 0.05 , level of significance. Tables and $P$ Values were generated.

Data from samples without signed consent forms and consent forms without samples were exempted.

\begin{tabular}{|c|c|c|c|c|}
\hline SCHOOL & NUMBER OF & NUMBER OF & SEX & \\
\hline CODES & SAMPLES EXAMINE & POSITIVES SAMPLES (\%) & MALES (\%) & FEMALES (\%) \\
\hline A & 47 & $5(1.1)$ & $3(0.6)$ & $2(0.4)$ \\
\hline B & 44 & $3(0.7)$ & $3(0.6)$ & $0(0.0)$ \\
\hline $\mathrm{C}$ & 131 & $19(4.0)$ & $10(2.3)$ & $9(2.0)$ \\
\hline $\mathrm{D}$ & 3 & $0(0.0)$ & $0(0.0)$ & $0(0.0)$ \\
\hline
\end{tabular}

\section{Result}

Microscopic examination of the urine samples reveal the presence of Ova of Schistosoma haematobium, epithelial cells, cast cells and crystals. The urine dip strip was used to detect microhaematuria, proteinuria, nitrite, leucocytes and $\mathrm{pH}$.

Table 1. Prevalence for Ova of Schistosoma haematobium. 


\begin{tabular}{lllll}
\hline SCHOOL & NUMBER OF & NUMBER OF & SEX & FEMALES (\%) \\
\hline CODES & SAMPLES EXAMINE & POSITIVES SAMPLES (\%) & MALES (\%) & $0(0.0)$ \\
\hline E & 43 & $3(0.7)$ & $3(0.6)$ & $4(1.0)$ \\
F & 108 & $12(2.6)$ & $8(1.8)$ & $3(0.6)$ \\
G & 42 & $6(1.1)$ & $2(0.4)$ & $3(0.6)$ \\
H & 44 & $53(11.5)$ & $3(0.6)$ & $21(4.6)$ \\
TOTAL & 462 & $32(6.9)$ & \\
\hline
\end{tabular}

The Table 1 above shows that 462 students were screened for the Ova of Schistosoma haematobium and 53 of them were positive. The prevalence of $11.5 \%$ was observed.

Table 2. Presence of Proteinuria.

\begin{tabular}{lllll}
\hline SCHOOL & NUMBER OF & NUMBER OF & POSITIVE SAMPLES & FEMALES (\%) \\
\hline CODES & SAMPLES EXAMINE & POSITIVES SAMPLES (\%) & MALES (\%) & $8(1.7)$ \\
\hline A & 47 & $13(2.8)$ & $5(1.1)$ & $5(1.1)$ \\
B & 44 & $10(2.2)$ & $5(1.1)$ & $46(10.0)$ \\
C & 131 & $81(17.5)$ & $35(7.6)$ & $0(0.0)$ \\
D & 3 & $0(0.0)$ & $0(0.0)$ & $5(1.1)$ \\
E & 43 & $8(1.7)$ & $3(0.6)$ & $38(8.2)$ \\
F & 108 & $68(14.7)$ & $30(6.5)$ & $6(1.3)$ \\
G & 42 & $12(2.6)$ & $6(1.3)$ & $7(1.5)$ \\
H & 44 & $15(3.3)$ & $8(1.7)$ & $115(24.9)$ \\
TOTAL & 462 & $207(44.8)$ & $92(19.9)$ & \\
\hline
\end{tabular}

The Table 2 above shows that 462 students were screened for proteinuria and 207 of them were positive. The prevalence of $44.8 \%$ was observed.

Table 3. Presence of Microhaematuria.

\begin{tabular}{|c|c|c|c|c|}
\hline SCHOOL & NUMBER OF & NUMBER OF & POSITIV & \\
\hline CODES & SAMPLES EXAMINE & POSITIVES SAMPLES (\%) & MALES & FEMALES \\
\hline $\mathrm{A}$ & 47 & $10(2.2)$ & $4(0.9)$ & $6(1.3)$ \\
\hline B & 44 & $6(1.3)$ & $3(0.6)$ & $3(0.6)$ \\
\hline $\mathrm{C}$ & 131 & $42(9.1)$ & $12(2.6)$ & $30(6.5)$ \\
\hline $\mathrm{D}$ & 3 & $0(0.0)$ & $0(0.0)$ & $0(0.0)$ \\
\hline $\mathrm{E}$ & 43 & $9(1.9)$ & $5(1.1)$ & $4(0.9)$ \\
\hline $\mathrm{F}$ & 108 & $26(5.6)$ & $11(2.4)$ & $15(3.3)$ \\
\hline G & 42 & $8(1.7)$ & $5(1.1)$ & $3(0.6)$ \\
\hline $\mathrm{H}$ & 44 & $5(1.1)$ & $2(0.4)$ & $3(0.6)$ \\
\hline TOTAL & 462 & $106(22.9)$ & $42(9.1)$ & $64(13.8)$ \\
\hline
\end{tabular}

The Table 3 above shows that 462 students were screened for Micro-Haematuria and 106 of them were positive. The prevalence of $22.9 \%$ was observed.

Table 4. Association between Micro-Haematuria with the Infection.

\begin{tabular}{|c|c|c|c|c|}
\hline \multirow{2}{*}{ Infection Status } & \multicolumn{4}{|c|}{ Presence of Micro-Heamaturia } \\
\hline & Positive & Negative & Total & \\
\hline Positive & 45 & 8 & 53 & \\
\hline Negative & 61 & 348 & 409 & \\
\hline Total & 106 & 356 & 462 & \\
\hline Chi-Square Value & & & & 130.009 \\
\hline$P$ Value & & & & 0.000 \\
\hline
\end{tabular}

The Table 4 above shows the relationship between Micro-Haematuria and Urinary Schistosomiasis. The $P$ Value was found to be 0.000 . The relationship was deducted from the 53 samples that were comfirmed positive to the Ova of the parasite.

Table 5. Association between Proteinuria and Urinary Schistosomiasis among Subjects.

\begin{tabular}{|c|c|c|c|c|}
\hline \multirow{2}{*}{ Infection Status } & \multicolumn{3}{|c|}{ Presence of Proteinuria } & \\
\hline & Positive & Negative & Total & \\
\hline Positive & 48 & 5 & 53 & \\
\hline Negative & 159 & 250 & 409 & \\
\hline Total & 207 & 255 & 462 & \\
\hline Chi-Square Value & & & & 50.694 \\
\hline$P$ Value & & & & 0.000 \\
\hline
\end{tabular}


The Table 5 above shows the relationship between Proteinuria and Urinary Schistosomiasis. The $P$ Value was found to be 0.000 . The 53 positive samples were used as standard for the association.

\section{Discussion}

The present study revealed $11.5 \%$ prevalence rate of urinary schistosomiasis among students in the selected secondary schools in Chikun Local Government Area based upon direct egg detection method, 22.9\% based on microhaematuria detection and $44.8 \%$ based on proteinuria. Urine from a healthy person does not contain nitrite. Nitrite and leukocyte esterase assist in the diagnosis of urinary tract infection [6].

Considering that the eggs can find their way to the female genital region and form granulomas in the uterus, fallopian tube and ovaries, if nothing is done soon, there will be high rate of infertility among the populace in the near future [12]. Schistosomtiasis can be cured without progressing to complications if there is an accurate diagnosis and prompt treatment during the initial stages of infection. Also, with prompt treatment, morbidity can be reversed during the early stages of chronic infection. Treatment of all school-age children and fishermen is required once every 2 years until the prevalence of infection falls below the level of public health importance. It is also recommended u-to complement the praziquantel treatment with supplementary measures such as provision of sanitation facilities and health education [13; 14]. Reagent strips are cheap, fast, easy to use and can be readily integrated into the primary health care programme. But there may be gender bias in females which may lead to under-reporting or over-reporting (false positives). The contamination of urine with menstrual blood from a female that recently finished her menstrual cycle would yield false positive results for haematuria. A similar finding may be noted for leucocyturia and proteinuria. Several studies have confirmed that the detection of proteinuria and haematuria when used together is a better means to measure morbidity than when used separately [15].

Microhaematuria has also been associated with urinary schistosomiasis $P 0.000<0.05$. This finding agrees with the findings from other reseachers that 'Urine heme dipsticks have proved useful for monitoring the impact of PZQ treatment on S. haematobium in African communities and have been suggested as the recommended method for monitoring mass treatment programs for this schistosome species' [14]. Sousa -Figueiredo et al., (2009), observed similar occurrence [16-19]. Haematuria arises when migrating eggs puncture small capillaries of the vesical plexus to get into the bladder. Haematuria was the first sign to be associated with schistosomiasis. Haematuria is usually seen at the end of urination (terminal haematuria), although haematuria throughout micturition may be seen in some severely infected cases [20].

The presence of micro proteinuria has been associated with urinary schistosomiasis $P 0.000<0.05$. This observation agrees with Weerakoon et al., (2015) that proteinuria has been shown to be clearly associated with urinary schistosomiasis which was in line with findings by Ugbomoiko et al., (2009) [5, 14, 21]. The eggs are metabolically very active and secrete more than a thousand proteins to facilitate passage through tissue planes [22].

However, other disease can also precipitate proteinuria and haematuria in other word, they are not specific. High levels of urinary protein in $S$. haematobium infection has been linked with nephritis, nephritic syndrome and bladder pathology. Some authors have cited the reversibility of proteinuria after treatment to support the renal origin of proteinuria. It is now generally accepted that bilharzial proteinuria is of post -renal origin and not a sign of impaired renal function [23].

The high sensitivity and specificity of Haematuria (HU) and Proteinuria (PU) testing, shows that it can be used as good screening test for S. haematobium infection [24].

\section{Conclusion}

The sensitivity of Urine dip strip when compared to direct egg detection methods, shows that there is high sensitivity on the use of urine dip strip. Statistical data $(P 0.000<0.05)$ has shown that the urine dip strip could be reliable in the survey for urinary Schistosomiasis. The use of urine dip strip is faster, does not need expertise and can be used in the field.

\section{Reference}

[1] Yirenya-Tawiah, D. R., Rashid A. A., Futagbi, G., Aboagye, I. and Dade, M (2011). Prevalence of Snail Vectors of Schistosomiasis in the Kpong Head Pond, Ghana. West African Journal of Applied Ecology 18: 39-45.

[2] World Health Organization (2015). Schistosomiasis. Fact Sheet number 115. WHO Press.

[3] World Health Organization (2010). Working to Overcome the Global Impact of Neglected Tropical Diseases. First WHO Report on Neglected Tropical Diseases. Geneva, Switzerland: WHO Press.

[4] Carter Center (2015). Schistosomiasis Control Program. Schistosomiasis-Fact. Atlanta, U.S.A.: One Copenhill.

[5] Ugbomoiko, U. S., Obiezue, R. N. N., Ogunniyi, T. A. B. and Ofoezie, I. E. (2009). Diagnostic accuracy of different urine dipsticks to detect urinary schistosomiasis: a comparative study in five endemic communities in Osun and Ogun States, Nigeria. Journal of Helminthology. 83: 203-209.

[6] Cheesbrough, M. (2006). District Laboratory Practice in Tropical Countries Part 2 (2 Ed) New York, USA: Cambridge University Press. Pp. 105-112.

[7] Nassef, M. O. and Olugboye, M. O. (1979). The hydrology and hydrogeology of Galma Basin. Unpub, File Report, Federal Department of Water Resources, Nigeria.

[8] Federal Ministry of Information (FMI). (2000). NIGERIA: A people united, a future assured. Vol. 2, Survey of states. 
[9] Olaniyan, I. O. and Tsuzom, J. N. (2014). An Appraisal of Certain Characteristics of Aquifer in Chikun Local Government Area of Kaduna, Nigeria. International Journal of Engineering Science \& Advanced Technology 4(6): 554-559.

[10] Arya, R., Antonisamy, B., Kumar, S., (2012). Sample Size Estimation in Prevalence Studies. Indian journal of Paediatrics 99(11):1482-1488.

[11] Omenesa, H. O., Bishop H. G. and Raji, H. M (2015). Prevalence of Urinary Schistosomiasis Among Pupils Attending Primary Schools In Bomo Village, Zaria-Nigeria. International Journal of Research in Engineering and Science 3(5): 2320-9356.

[12] Toller, A., Scopin, A. C., Apfel, V., Prigenzic, K. C., Tsob, F. K., Focchic, G. R., Speckb, N., Ribaltab, J. (2015). An interesting finding in the uterine cervix: Schistosoma hematobium calcified eggs. Autopsy Case Report 5 (2):41-44.

[13] Utzinger, J., Raso, G., Brooker, S., Savigny, D. D., Tanner, M., Ornbjerg, N., Singer, B. H. And N'goran, E. K. (2009). Schistosomiasis and Neglected Tropical Diseases: Towards Integrated and Sustainable Control and A Word of Caution. Parasitology 136: 1859-1874.

[14] Weerakoon, K. G. A. D., Gobert, G. N., Cai, P. and McManusa, D. P. (2015). Advances in the Diagnosis of Human Schistosomiasis. Clinical Microbiology Reviews, 28 (4): 939967.

[15] Ugbomoiko, U. S., Ofoezie, I. E., Okoye, I. C., Heukelbach, J. (2010). Factors associated with urinary schistosomiasis in two peri-urban communities in south-western Nigeria. Ann Tropical and Medical Parasitology 104 (5):409-19.

[16] Sousa-Figueiredo, J. C., Basa'ñ ez, M., Khamis, I. S., Garba, A., Rollinson, D., Stothard J. R. (2009). Measuring Morbidity Associated with Urinary Schistosomiasis: Assessing Levels of Excreted Urine Albumin and Urinary Tract Pathologies. PloS Neglected Tropical Diseases 3(10): e526.

[17] Knopp, S., Becker, S. L., Ingram, K. J., Keiser, J. and Utzinger,
J. (2013). Diagnosis and Treatment of Schistosomiasis in Children in the Era of Intensified Control. Expert Reviews of Anti Infection Therapy. 11(11): 1237-1258.

[18] Bassiouny, H. K., Hasab, A. A., El-Nimr, N. A., Al-Shibani, L. A. and Al- Waleedi, A. A. (2014). Rapid diagnosis of Schistosomiasis in Yemen Using a Simple Questionnaire and Urine Reagent Strips. Eastern Mediterranean Health Journal 20(4):242-249.

[19] Bocanegra, C., Gallego, C., Mendioroz, J., Moreno, M., Sulleiro, E., Salvador, E., Sikaleta, N., Nindia, A., Tchipita, D., Joromba, M., Kavaya, S., Montalvá, A. S., López, T. and Molina, I. (2015). Epidemiology of Schistosomiasis and Usefulness of Indirect Diagnostic Tests in School-Age Children in Cubal, Central Angola. Plos Neglected Tropical Diseases, 9 (10): 1-11.

[20] Useh, M. F. (2013). Schistosomiasis. InTech Open Science 4: 63-93.

[21] Young. N. D., Jex, A. R., Li, B., Liu, S., Yang, L., Xiong, Z., Li, Y., Cantacessi, C., Hall, R. S., Xu X., Chen, F., Wu, X., Zerlotini, A., Oliveira, G., Hofmann, A., Zhang, G., Fang, X., Kan, Y., Campbell B. E., Loukas, A., Ranganathan, S., Rollinson, D., Rinaldi, G., Brindley, P. J., Yang, H., Wang, J., Wang, J. and Gasser, R. B. (2012). Whole-Genome Sequence of Schistosoma haematobium. Nature Genetics 44(2): 221-227.

[22] Walz, Y., Wegmann, M., Dech, S., Raso, G. and Utzinger, J. (2015). Risk Profiling of Schistosomiasis using Remote Sensing: Approaches, Challenges and Outlook. Parasites \& Vectors, 8(163): 1-16.

[23] Useh, M. F. (2013). Schistosomiasis. InTech Open Science 4: 63-93.

[24] Mohammed, K., Hassan, J., Opaluwa, S. A., Adamu, T., Nataala, S. U., Garba, M. K., Bello M. and Bunza, N. M., (2017). Diagnostic Potentials of Haematuria and Proteinuria in Urinary Schistosomiasis among School-Age Children in Aliero Local Government Area, Kebbi State, North-Western Nigeria. Asian Journal of Research in Medical and Pharmaceutical Sciences 2(4): 1-9. 